\title{
Review Article \\ Hypoxia Inducible Factor Pathway and Physiological Adaptation: A Cell Survival Pathway?
}

\author{
Hemant Kumar and Dong-Kug Choi \\ Department of Biotechnology, Konkuk University, Chungju 380-701, Republic of Korea \\ Correspondence should be addressed to Dong-Kug Choi; choidk@kku.ac.kr
}

Received 21 November 2014; Accepted 28 December 2014

Academic Editor: Elio Ziparo

Copyright ( $) 2015$ H. Kumar and D.-K. Choi. This is an open access article distributed under the Creative Commons Attribution License, which permits unrestricted use, distribution, and reproduction in any medium, provided the original work is properly cited.

\begin{abstract}
Oxygen homeostasis reflects the constant body requirement to generate energy. Hypoxia $\left(0.1-1 \% \mathrm{O}_{2}\right)$, physioxia or physoxia ( 1$13 \%)$, and normoxia ( 20\%) are terms used to define oxygen concentration in the cellular environment. A decrease in oxygen (hypoxia) or excess oxygen (hyperoxia) could be deleterious for cellular adaptation and survival. Hypoxia can occur under both physiological (e.g., exercise, embryonic development, underwater diving, or high altitude) and pathological conditions (e.g., inflammation, solid tumor formation, lung disease, or myocardial infarction). Hypoxia plays a key role in the pathophysiology of heart disease, cancers, stroke, and other causes of mortality. Hypoxia inducible factor(s) (HIFs) are key oxygen sensors that mediate the ability of the cell to cope with decreased oxygen tension. These transcription factors regulate cellular adaptation to hypoxia and protect cells by responding acutely and inducing production of endogenous metabolites and proteins to promptly regulate metabolic pathways. Here, we review the role of the HIF pathway as a metabolic adaptation pathway and how this pathway plays a role in cell survival. We emphasize the roles of the HIF pathway in physiological adaptation, cell death, pH regulation, and adaptation during exercise.
\end{abstract}

\section{Introduction}

Hypoxia inducible factor (HIF) senses and coordinates cellular responses to hypoxia. HIF is a heterodimer consisting of one of three alpha $(\alpha)$ subunits and a beta $(\beta)$ subunit. HIF$\beta$ is constitutively expressed, whereas HIF- $\alpha$ is induced by hypoxia. HIF- $1 \alpha$ is the most well-established member of the HIF family; the other two members of the basic-helix-loophelix-PAS (bHLH-PAS) superfamily are HIF- $2 \alpha$ (endothelial PAS domain protein 1 or HIF $\alpha$-like-factor), which also stabilizes hypoxia and binds to the aryl hydrocarbon receptor nuclear translocator (ARNT) $[1,2]$ and HIF-3 $\alpha$ [3]. HIF-1 $\alpha$ is a transcriptional activator and a master regulator for the expression of genes involved in the response to hypoxia in most mammalian cells [4]. HIF-1 $\alpha$ is prolyl hydroxylated at P402 and P564 in its oxygen-dependent degradation domain (ODD) under normoxic conditions. This leads to binding of the HIF- $\alpha$ unit to the E3 ubiquitin ligase von Hippel-Lindau protein (pVHL) at L574 for degradation $[5,6]$. Homologous proline and leucine residues in HIF- $2 \alpha$ also play similar roles [7]. HIF-1/2 $\alpha$ transactivation activity is further inhibited by asparaginyl hydroxylation under normoxic conditions [8]. Low oxygen tension stabilizes the $\alpha$-subunit and leads to nuclear translocation, formation of a dimer with HIF- $1 \beta$, and recruitment of transcriptional coactivators [9]. This complex binds to an enhancer domain of the hypoxia responsive element (HRE) located either at the $5^{\prime}$ or $3^{\prime}$ region of target genes, including heme oxygenase-1, vascular endothelial growth factor (VEGF), glucose transporter (GLUT)1 , and GLUT-4 [10]. Interestingly, HIF-1 $\alpha$ also upregulates glycolytic enzymes and glucose transporters, allowing cells to depend more heavily on glycolysis for energy [11], suggesting that HIF- $1 \alpha$ also modulates aerobic metabolism. The vast majority of HIF target genes are regulated by HIF- $1 \alpha$, whereas exclusively HIF- $2 \alpha$-dependent genes are scarce and cell type-dependent [12-15]. Most reports show that HIF$1 \alpha$ and HIF- $2 \alpha$ are master regulators of the transcriptional response to hypoxia, but the role of HIF- $3 \alpha$ under hypoxic conditions is far less clear. HIF- $3 \alpha$ is the newest member of the family and may be more restricted than the other 
HIF subunits [3]. HIF-3 $\alpha$ mRNA may also be activated by hypoxia [16]. Evidence suggests that HIF-3 $\alpha$ may be functionally distinct. HIF- $3 \alpha$ sequence has relatively low identity with HIF- $1 \alpha / 2 \alpha$ [3]. HIF- $1 \alpha$ and HIF- $2 \alpha$ have two terminal transactivation domain (TADs) $[1,10]$, whereas HIF- $3 \alpha$ has only one TAD. HIF- $3 \alpha$ has a unique leucine zipper domain and an LXXLL motif [3], and these unique structural features are evolutionarily conserved [17]. HIF-3 $\alpha$ has multiple splice variants, and the inhibitory PAS domain protein is the most studied, which is a truncated protein and a dominant-negative inhibitor of HIF- $1 \alpha$ [18]. HIF- $1 \alpha$ and HIF- $2 \alpha$ have $48 \%$ amino acid sequence identity and similar protein structures, but are nonredundant and have distinct target genes and mechanisms of regulation. Interestingly, HIF- $1 \alpha$ appears the most active isoform during short periods $(2-24 \mathrm{~h})$ of intense hypoxia or anoxia $\left(<0.1 \% \mathrm{O}_{2}\right)$ in some cell lines, whereas HIF- $2 \alpha$ is active under mild or physiological hypoxia $\left(<5 \% \mathrm{O}_{2}\right)$, and continues to be active even after $48-$ $72 \mathrm{~h}$ of hypoxia [19]. Thus, in some contexts, HIF- $1 \alpha$ plays key role in initial response to hypoxia whereas HIF- $2 \alpha$ drives the hypoxic response during chronic hypoxic exposure [19, 20]. This HIF "switch" results between HIF- $\alpha$ and HIF- $2 \alpha$ suggests physiological and pathological adaptation required to adapt for cell survival. Interestingly, these isoform plays opposite but balancing roles during the hypoxic response under both physiological and pathophysiological conditions in some cells.

\section{Prolyl Hydroxylases: Oxygen Sensors}

Prolyl hydroxylases (PHDs) [1, 2 and 3] are evolutionary conserved oxygen sensors in metazoans. These dioxygenases were discovered after confirming that oxygen-dependent enzymatic activity covalently modifies an HIF- $1 \alpha$ domain known as the ODD domain [21-23]. PHDs require 2oxoglutarate as a cosubstrate, molecular oxygen, and iron liganded by two histidine and one aspartic acid residues to function as hydroxylases. PHDs play a key role in the HIFmediated hypoxia signaling pathway, which facilitates cell survival and adaptation in response to capricious environmental oxygen levels [24]. Selective knockdown of PHDs enhances HIF-dependent gene expression in vitro [25]. PHDs lose their activity under hypoxic conditions, leading to accumulation and nuclear translocation of HIF- $\alpha$ and activation of HIF target genes by binding to HREs [26]. The first identified function of PHDs was to hydroxylate human HIF-1 $\alpha$ hsubunits at Pro402 and Pro564 under normoxic conditions, resulting in their recognition, pVHL ubiquitylation, and degradation by $26 \mathrm{~S}$ proteasomes. The PHD catalytic domain recognizes a specific LXXLAP motif in the ODD of the HIF$\alpha$ subunits [27]. PHD1-3 have near ubiquitous tissue expression; PHD-2 is generally the most abundant isoform, with the exception of the testis, where PHD-1 is the most highly expressed isoform, and the heart, where PHD-3 expression predominates [28]. Loss of PHD-1 lowers skeletal muscle and liver oxygen consumption by reprogramming glucose metabolism from primarily oxidative to more anaerobic ATP production, suggesting selective loss of PHD-1-induced hypoxia tolerance $[29,30]$. Knockdown of the Phd-2 gene, but not those of Phd-1 and Phd-3, results in embryonic death due to placental and heart defects, suggesting that PHD-2 is essential during mouse embryogenesis [31]. Interestingly, broad spectrum conditional Phd-2 knockout in adult mice leads to hyperactive angiogenesis, angiectasia, and congestive heart failure, suggesting that PHD-2 is a major negative regulator of vascular growth $[32,33]$. Furthermore, PHD-3 is required for proper anatomical and physiological integrity of the system, as loss of PHD-3 results in abnormal sympathoadrenal development and systemic hypotension [34]. Targeted deletion of the PHD-3 gene increases angiogenesis and preserves cardiac function by stabilizing HIF- $1 \alpha$ after infarction, suggesting a potential target for pharmacological management of ischemic myocardial disease [35].

\section{Hypoxia and Reactive Oxygen Species}

Oxygen scarcity leads mitochondria to produce reactive oxygen species (ROS) thereby giving alert to cells to the shortage. ROS describe a range of molecules and free radicals (chemical species with one unpaired electron) derived from molecular oxygen. The mitochondrial electron transport chain contains several redox centers that may leak electrons to oxygen, constituting the primary source of superoxide (precursor of most ROS) in most tissues. Superoxide anion is produced both enzymatically and nonenzymatically in vivo. Enzymatic sources include NADPH oxidases [36, 37] as well as cytochrome P450-dependent oxygenases [38]. Proteolytic conversion of xanthine dehydrogenase to xanthine oxidase provides another enzymatic source of both superoxide and $\mathrm{H}_{2} \mathrm{O}_{2}$ (and therefore constitutes a source of $\mathrm{OH}^{*}$ ) and has been proposed to mediate deleterious processes in vivo [39]. Nonenzymatic production of superoxide occurs when a single electron is directly transferred to oxygen by reduced coenzymes or prosthetic groups or by xenobiotics previously reduced by enzymes. According to the equation

$$
\frac{\mathrm{d}[\text { superoxide }]}{\mathrm{d} t}=k\left[\mathrm{O}_{2}\right]\left[\mathrm{R}^{*}\right] \text {, }
$$

where $\mathrm{R}^{\bullet}$ is an electron donor, the rate of superoxide formation increases with oxygen concentration under normobaric and hyperbaric conditions [40]. As predicted by (1), mitochondrial production of superoxide anion should increase with oxygen concentration, but the proportion of superoxide anion is less than predicted in tissue exposed to atmospheric oxygen [41, 42]. ROS activate the HIF pathway during hypoxia leading to stabilization of the $\operatorname{HIF}(\mathrm{s}) \alpha$-isoform. The generation of ROS should decrease with hypoxia according to (1), yet many reports show increased oxidative stress under moderately hypoxic conditions [43-45] but not under severe hypoxic conditions [44]. Moreover, substantial evidence indicates a role for the functional respiratory chain in the generation of ROS under hypoxic conditions. A mutation in the respiratory chain $[45,46]$ or complex 1 inhibitors [47] prevent stabilization of HIF under hypoxic conditions. More research is needed to clarify the paradoxical ROS formation in the response of tissues to hypoxia. 


\section{Hypoxia and Mitochondrial Respiration}

Mitochondria are the largest consumers of cellular $\mathrm{O}_{2}$ and are likely candidates for the location of a cellular oxygen sensor. Mitochondria are both targets and important sources of free radicals [48]. Most vital intracellular processes, including blood vessel maintenance, heart contractibility, lung functioning, and neurotransmitter and hormonal support require mitochondria. Mitochondria are the source of ATP and maintain oxygen homeostasis at both the systemic and cellular levels [49]. Initial evidence supporting mitochondria as an oxygen sensor came with the discovery that mitochondrial-depleted Hep3B cells fail to respire and activate mRNAs of erythropoietin, glycolytic enzymes, or VEGF during hypoxia. These cells also fail to increase the generation of ROS during hypoxia, suggesting that mitochondrial (mt) ROS trigger hypoxia-induced transcription [45]. Mitochondria are implicated in multiple HIF-dependent and independent pathways through production of mtROS. Interestingly, decreasing mtROS levels with mitochondrial inhibitors or ROS scavengers prevents stabilization of HIF- $1 \alpha$ under hypoxic conditions, suggesting that ROS are important for this effect [45-47]. Interestingly, murine embryonic cells lacking cytochrome $c$, and therefore mitochondrial activity, have impaired cellular oxygen sensing, which prevents stabilization of HIF- $1 \alpha$ and HIF- $2 \alpha$ under hypoxic conditions, suggesting that mtROS act upstream of PHD to regulate HIF$1 \alpha$ and HIF-2 $\alpha$ [50]. Mitochondrial complex III is required for hypoxia-induced ROS production and cellular oxygen sensing [51, 52]. Similarly, embryonic stem cells lacking cytochrome $c$ fail to stabilize HIF-1 $\alpha$ during hypoxia, as loss of cytochrome $c$ leads to complete reduction of cytochrome $\mathrm{cl}$ and the rieske iron-sulfur protein, which inhibit transfer of electrons from ubiquinol at the $\mathrm{Q}_{o}$ site [50]. The complex III $\mathrm{Q}_{o}$ site is necessary to increase cytosolic ROS under hypoxic conditions, which inhibits $\mathrm{PHDs}$ from degrading the HIF- $1 \alpha$ protein [53]. Additionally, exogenous $\mathrm{H}_{2} \mathrm{O}_{2}$ or mutations leading to $\mathrm{H}_{2} \mathrm{O}_{2}$ accumulation stabilize HIF- $1 \alpha$ during normoxia [52, 54]. In accordance, antioxidants abolish the hypoxic HIF response, suggesting that generation of $\mathrm{mtROS}$ is responsible for propagating the hypoxic signal [45].

\section{Physiological Adaptation by HIF(s)}

5.1. Physiological Importance of $\operatorname{HIF}(s)$. The role of the HIF pathway has been demonstrated under hypoxic conditions but it also plays an important role in normoxia. The physiological roles of HIF- $1 \alpha$ and HIF- $2 \alpha$ are not known in detail. Hif $1 \alpha^{-} /^{-}$knockout mice have cardiac and vascular malformations and embryos die around mid-gestation [55], whereas HIF- $2 \alpha$ knockout mice die presumably of bradycardia due to an inadequate supply of catecholamines during embryonic development [56]. HIF-1 $\alpha$ is present in mice under normoxic conditions, increases within distinct cell types in response to systemic hypoxia, and plays an important role in oxygen homeostasis [57]. HIF- $2 \alpha$ plays an important role in cardiovascular development and angiogenesis [56, 58]. Murine embryonic stem cells lacking the HIF- $2 \alpha$ gene revealed an association with the response to hypoglycemia rather than hypoxia, suggesting that HIF- $2 \alpha$ may be more important in the survival response than oxygen level [59]. Hypoxia affects expression of the PER1 and CLOCK circadian genes, and HIF-1 $\alpha$ interacts with PER1 under normoxic conditions [60]. The mouse Hifla gene is expressed from two distinct promoter/first exon combinations, resulting in tissue-specific (mHIF-1alphaI.1) and ubiquitous (mHIF-1alphaI.2) forms. mHIF-1alphaI.1 is a novel HIF- $1 \alpha$ mRNA isoform exclusively detected in elongated spermatids. The mHIF-1alphaI.1 protein is located in the mid-piece of the spermatozoal flagellum and expression is oxygen independent [61]. The mHIF1alphaI.1 isoform is also upregulated in activated T cells under normoxic conditions, suggesting a physiological role for the mHIF-1alphaI.1 isoform in activated lymphocytes [62]. Interestingly, mice exposed to an elevated temperature strongly upregulate HIF-1 $\alpha$ in the liver, kidney, and spleen, suggesting a novel mechanism to stabilize HIF-1 $\alpha$ under normoxic conditions [63]. Furthermore, a recent study demonstrated that treating normal human cells with low-dose radiation induces a HIF-1-mediated adaptive and protective metabolic response and increased radiation resistance [64]. HIF- $1 \alpha$ is induced and activated at physiological oxygen tensions in a mitogen activated protein kinase-dependent manner and determines the increased cell proliferation rate that is common under these conditions [65]. HIF-1 $\alpha$ plays an important role in the adaptation of myocardium to mechanical stress via stressactivated channels [66]. As discussed previously, HIF- $1 \alpha$ is required for mesenchymal cell survival, and HIF knockout mice have malformed cardiovascular systems and neural tube defects and die during mid-gestation $[55,67,68]$. Hypoxia potentiates interleukin (IL)-1 $\beta$ expression and attenuates selective targeting of IL-1 $\beta$ to autophagic degradation in activated macrophages, suggesting that a novel proinflammatory mechanism may participate in atherogenesis [69]. These observations support the notion that the HIF pathway plays important roles in physiological adaptation and is required for normal growth and development. Interestingly, mice with only one HIF- $1 \alpha$ mutant allele develop normally but have impaired physiological responses to chronic hypoxia, such as reduced polycythemia, right ventricular hypertrophy, pulmonary hypertension, pulmonary vascular remodeling, and electrophysiological responses [70,71]. The carotid body (CB) monitors arterial blood $\mathrm{O}_{2}$ levels and stimulates breathing in response to hypoxemia to ensure an adequate $\mathrm{O}_{2}$ supply. Both HIF- $1 \alpha$ and HIF- $2 \alpha$ are expressed in the CB [56, 72], and $\mathrm{CB}$ responses to hypoxia are impaired in Hifl $\alpha+/-$ mice [73], whereas they are exaggerated in Hif2 $\alpha+/-$ mice [74]. Balanced HIF- $1 \alpha$ and HIF- $2 \alpha$ activity is critical for oxygen sensing by the $\mathrm{CB}$ and adrenal medulla and for their control of cardiorespiratory function [75]. Similarly, CBs isolated from HIF- $1 \alpha$ heterozygous mice have a dramatic effect on neural activity and ventilatory adaptation after exposure to hypoxia, suggesting a role for HIF-1 $\alpha$ at the systemic level [73]. Partial HIF- $2 \alpha$ deficiency leads to increased levels of HIF- $1 \alpha$ and NADPH oxidase 2, resulting in an oxidized intracellular redox state, exaggerated hypoxic sensitivity, and cardiorespiratory abnormalities, which are reversed by treatment with a HIF- $1 \alpha$ inhibitor or a superoxide anion scavenger. In contrast, partial HIF- $1 \alpha$ deficiency increases levels of HIF- $2 \alpha$ and 
superoxide dismutase 2, leading to a reduced intracellular redox state, blunted oxygen sensing, and impaired $\mathrm{CB}$ and ventilatory responses to chronic hypoxia, which are corrected by a HIF- $2 \alpha$ inhibitor. These observations demonstrate that the redox balance, which is determined by mutual antagonism between HIF- $\alpha$ isoforms, establishes the hypoxic sensing set-point by the $\mathrm{CB}$ and adrenal medulla and is required for maintenance of cardiorespiratory homeostasis [75]. HIF$2 \alpha$ plays an important role during the postvasculogenesis stages and is required to remodel the primary vascular network into a mature hierarchical pattern [58]. HIF- $2 \alpha$ sense hypoxia during mid-gestational development and translate this signal into an altered gene expression pattern, leading to increased circulating catecholamine levels and proper cardiac function [56]. Despite of normoxic environment several tissues are inherently hypoxic suggesting importance of HIF pathway in normal development. Interestingly, tissue-specific targeting to delete HIF- $1 \alpha$ in the cartilaginous growth plate of developing bone showed gross skeletal malformations and die perinatally, probably due to tracheal abnormalities suggesting the role of hypoxia in growth plate development [76]. In addition, hypoxic environment is essential for appropriate embryonic development and placentation. Oxygen tension determines whether cytotrophoblasts, specialized placental cells proliferate or invade, thereby regulating placental growth and cellular architecture [77]. Moreover, ARNT knockout mice placentas shows greatly reduced labyrinthine and spongiotrophoblast layers, and increased numbers of giant cells supporting that HIF-1 $\alpha$ is essential for mammalian placentation [78]. Additionally, HIFs play important roles in modulating the developmental plasticity of stem cells by integrating physiological, transcriptional and epigenetic inputs in placenta [79]. Transforming growth factor (TGF) $\beta-3$, an inhibitor of extravillous trophoblast differentiation, partly mediates oxygen-regulated early events of trophoblast differentiation through HIF-1 $\alpha$ pathway [80]. In addition, HIF-lalpha-deficient mouse embryonic fibroblasts showed impaired migratory capabilities and demonstrated that TGF$\beta-3$ manifests hypoxia and HIF- $1 \alpha$-dependent regulation [81]. Furthermore, hypoxia signaling plays a central role in cartilage, bone, and hematopoiesis [82]. HIF-1 $\alpha$ plays a bimodal role in cartilage homeostasis by enhancing anaerobic glycolysis and inhibiting apoptosis suggesting the potential role of this pathway in treatment of osteoarthritis [83, 84]. HIF- $2 \alpha$, was found to be essential for endochondral ossification of cultured chondrocytes and embryonic skeletal growth in mice and its function are independent of oxygen-dependent hydroxylation [85]. Elevated levels of HIF-1 $\alpha$ promotes cartilage formation and maintenance whereas elevated levels of HIF- $2 \alpha$ favors cartilage destruction and endochondral ossification $[85,86]$. Taken together this suggests that both HIF- $1 \alpha$ and HIF- $2 \alpha$ plays an important role for normal growth and development of skeletal vasculature.

5.2. Regulation of Metabolic Pathways. Increased glycolysis during hypoxia is a crucial step to meet energy demands. Interestingly, HIF-1 $\alpha$ stimulates glycolysis and actively represses mitochondrial function and oxygen consumption by inducing pyruvate dehydrogenase kinase-1 (PDK1) activity [87]. That study also reported that PDK-1 phosphorylates and inhibits pyruvate dehydrogenase from using pyruvate to fuel the mitochondrial TCA cycle, which decreases mitochondrial oxygen consumption resulting in a relative increase in intracellular oxygen tension [87]. Another known mechanism to increase respiration efficiency in hypoxic cells is by regulating of cytochrome $c$ oxidase (COX) activity. COX is located in the inner mitochondrial membrane and is a dimer composed of monomers with 13 subunits [88]. Subunits I, II, and III are encoded by the mitochondrial genome, constitute the catalytic core of the enzyme, and are highly conserved in eukaryotes. The crystal structure of bovine COX reveals that subunit IV (COX4) interacts with both COX1 and COX2 [88]. The first step of COX assembly in mammalian cells is the association of COX1 with COX4 [89]. COX4 binds ATP, within the complex, leading to allosteric inhibition of $\mathrm{COX}$ activity at high ATP/ADP ratios and demonstrating a regulatory role for COX4 [90]. Under hypoxic conditions, HIF-1 $\alpha$ mutually regulates COX4 subunit expression by stimulating transcription of the genes encoding COX4-2 and LON, a mitochondrial protease required for COX4-1 degradation. The effects of manipulating COX-4 subunit expression on COX activity, ATP production, $\mathrm{O}_{2}$ consumption, and ROS generation indicate that the COX4 subunit switch is a homeostatic response that optimizes respiration efficiency at different $\mathrm{O}_{2}$ concentrations [11]. Simply, PDK-1 inhibits conversion of pyruvate to acetyl-CoA, thereby preventing pyruvate entry into the TCA cycle and the COX- 4 subunits govern mitochondrial respiration efficiency in response to varied oxygen tensions [11, 87]. Autophagy may be the fourth adaptive metabolic response required to prevent increased ROS levels and cell death in hypoxic cells [91]. Mitochondria are replaced every 2-4 weeks in rat brain, heart, liver, and kidney [92]. The destruction of mitochondria is believed to occur via autophagy [93, 94]. Autophagy can be induced by environmental stress such as nutrient deprivation and provides a mechanism to dispose of damaged mitochondria [95, 96]. Autophagy is induced in the heart subject to hypoxic or ischemic conditions and has been proposed to play either a protective or pathogenic role in heart disease [96-98]. BNIP3 is an accepted HIF-1 target gene $[99,100]$ and is associated with autophagy [98]. BNIP3 may disrupt interactions between Beclin-1, a highly conserved protein required to initiate autophagy, and $\mathrm{Bcl} 2$ or Bcl-XL [101]. In contrast to HIF, c-MYC is a proto-oncogene that codes for a transcription factor, regulates the expression of $10-15 \%$ of all genes in the genome $[102,103]$, and promotes mitochondrial respiration by increasing biogenesis [103]. Under physiological conditions HIF- $1 \alpha$ inhibits c-MYC activity by directly interacting and stimulating a proteasome-dependent pathway $[104,105]$. c-Myc paradoxically collaborates with Hif- 1 under stress conditions to induce PDK-1 and hexokinase 2 expression followed by aerobic glycolysis $[105,106]$ and angiogenesis [106]. 
5.3. Role of the HIF Pathway in Cell Proliferation and Cell Death. The role of HIF pathway in cell death is controversial; HIF-1 can induce apoptosis [107], prevent cell death, or even stimulate cell proliferation [108]. The oxygen concentration determines whether cell will go apoptosis or not; oxygen level in the range $0-0.5 \%$ could induce apoptosis whereas cells with oxygen levels in the range of $1-3 \%$ do not undergo apoptosis [109]. ATP is another key determinant of apoptosis; as long as cells have an enough supply of glycolytic ATP during oxygen deprivation, apoptosis can be executed [110]. Moreover, lack of oxygen inhibits the electron transport chain at the inner membrane of the mitochondria thereby causes a reduction in the membrane potential. This reduction of mitochondrial derived ATP causes activation of Bax or Bak, leading to cytochrome $\mathrm{C}$ release into the cytosol [111]. Cytochrome $\mathrm{c}$ is released and caspase- 9 is activated in oxygen-deprived cells undergoing apoptosis [110, 111]. Furthermore, p53 protein, an important regulator of apoptosis can induce the Bax and Bak proteins thereby initiating the cascade leading to apoptosis through cytochrome C [112]. Interestingly, fibroblasts from mice lacking both Bax and Bak genes are resistant to oxygen deprivation induced apoptosis [110]. Similarly, cell over-expressing Bcl-2 or BcL-XL, the anti-apoptotic proteins prevents oxygen deprivation induced apoptosis by inhibiting the release of cytochrome $c$ from the mitochondria [110, $113,114]$. In addition to energy deprivation, ROS generation contributes to hypoxia induced apoptosis. In this case, the initiator caspase 9 is cleaved directly to the active form by caspases 3 and 12, without the involvement of cytochrome $\mathrm{C}$ in response to hypoxia [115]. Activation of c-Jun NH2terminal kinase (JNK) is another mechanism by which hypoxia can induce apoptosis in melanoma cells [116].

HIF pathway is also involved in cell proliferation and promoting metastases $[117,118]$, VEGF is particularly noteworthy target gene of HIF pathway involved in cell proliferation and upregulated in most cancers [119, 120]. The HIFs can alter cell-cycle progression through putative transcriptional targets such as Cyclin D1 [121] and indirect modulation of p21 and p27 [122]. Furthermore, hypoxic induction of HIF$1 \alpha$ suppresses cell proliferation and acute HIF- $1 \alpha$ stabilization at moderate hypoxia $\left(1 \% \mathrm{O}_{2}\right)$ results in cell cycle arrest by inhibiting c-Myc transcriptional activity [122]. In contrast, HIF- $2 \alpha$ induction promotes cell cycle progression by enhancing c-Myc function [105].

5.4. Role of the HIF Pathway in pH Regulation and Exercise. The correlation between hypoxia and intracellular $\mathrm{pH}(\mathrm{pHi})$ was extensively researched in the 1980-90s. Rapid buildup of intracellular lactate and $\mathrm{H}^{+}$as well as an extensive decrease in phosphocreatine concentration is the first sign of hypoxia. ATP is more resistant to hypoxia provided that glucose is present. Furthermore, metabolic damage is considerably greater if glucose is absent during the insult, suggesting that either anaerobic ATP production or low $\mathrm{pH}$ may exert some protective effect against acute cell damage [123]. The regulation of $\mathrm{Na}^{+} / \mathrm{H}^{+}$exchange (NHE) and $\mathrm{pHi}$ is vital for maintaining cell viability. $\mathrm{pHi}$ modulates a number of important cell functions, including signal transduction pathways involved in the regulation of cell size and proliferation
[124-126]. Alterations in pHi are also associated with hypoxic pulmonary vasoconstriction $[127,128]$. Pulmonary arterial smooth muscle cells from chronic hypoxic mice have an elevated basal pHi accompanied by an increase in NHE activity, secondary to increased NHE1 isoform expression [129]. HIF-1 $\alpha$ plays an important role governing increased NHE, NHE1 expression, and alkalinization of pulmonary arterial smooth muscle cells in response to hypoxia [130]. Interestingly, NHE inhibitors attenuate hypoxia-induced apoptosis in cardiac myocytes [131]. Tumor cells have a lower extracellular $\mathrm{pH}(\mathrm{pHe})$ and a higher $\mathrm{pHi}$ than those of normal cells. Low pHe promotes invasiveness, whereas high $\mathrm{pHi}$ provides a competitive advantage to growth of tumor cells compared to normal cells for $[132,133]$. Low $\mathrm{pHe}$ results from lactic acid accumulation solely produced by glycolysis. Hypoxia induces coordinated upregulation of glycolysis, a potential step that may promote tumor cell growth and activate the capacity of tumor-associated carbonic anhydrase (CA) IX to acidify $\mathrm{pHe}$ thereby leading to tumor progression [134]. HIF- $1 \alpha$ controls CA IX and CA XII expressed by tumor cells. Hypoxia-inducible CAIX and CAXII proteins promote cell survival and growth by maintaining $\mathrm{pHi}$. Moreover, CAIX and CAXII constitute a robust pHi-regulating system that confers a tumor growth and survival advantage to cells exposed to a hypoxic and acidic microenvironment [135].

HIF is a candidate to facilitate training adaptation in skeletal muscle. Muscle training induces negative regulators of HIF (PHD, FIH, and sirtuin-6) but lowers PDK-1 expression in elite athletes, thereby contributing to skeletal muscle adaptation to exercise [136]. Endurance exercise improves muscle oxidative capacity [137], whereas resistance exercise training leads to increased muscle size and strength [138]. One study investigated the effects of 8 weeks of resistance exercise training performed under hypoxic (HRT) or normoxic conditions (NRT) on skeletal muscle. As results, significant increases in muscle endurance, plasma VEGF concentration, and capillary-to-fiber ratio were observed following training in the HRT group compared those in the NRT group, suggesting that HRT may also lead to increased muscular endurance and promote angiogenesis in skeletal muscle [139]. Chuvash polycythemia (CP) is an autosomal recessive disorder in which regulatory degradation of HIF is impaired, resulting in elevated levels of HIF under normal oxygen tensions $[140,141]$. Patients with CP show early and marked phosphocreatine depletion, higher blood lactate accumulation, acidosis in skeletal muscles, and reduced exercise capacity [142]. Interestingly, gene therapy with intramuscular administration of Ad2/HIF-1 $\alpha /$ VP16 was not effective for patients with intermittent claudication [143]. Pyruvate dehydrogenase $(\mathrm{PDH})$ plays an important role controlling the flux of pyruvate to acetyl-CoA. $\mathrm{PDH}$ is inactivated during acute hypoxia thereby promoting conversion of pyruvate to lactate, suggesting an influence of $\mathrm{PDH}$ activity on the fate of pyruvate [87]. The transition from acute to chronic hypoxia desensitizes the HIF- $1 \alpha$ pathway, leading to a re-establishment of PDH activity and reduced lactate production by exercising muscles [144]. Exercise with intermittent hypoxic training for 3 weeks causes a significant decrease in skeletal muscle HIF-1 $\alpha$ mRNA, suggesting that 
transcriptional and posttranscriptional regulation of the HIF1 differ in muscle and other cells [145]. HIF-1 $\alpha$ and HIF- $2 \alpha$ induce angiogenesis and improve muscle energy recovery [146]. In contrast, the HIF- $3 \alpha$ subunit plays a negative role in adaptation to hypoxia because inhibiting HIF-3 $\alpha$ expression leads to increased physical endurance [147].

\section{Conclusion}

In present review we have discussed the physiological adaptations and importance of the HIF pathway. Several studies have demonstrated that manipulating the HIF pathway can help treat diverse disorders. HIF(s) are also upregulated under inflammatory conditions, suggesting their role in maintaining homeostatic conditions and protecting against cellular inflammation. The role of the HIF pathway varies under diverse conditions. For example, HIF inhibitors have been developed to treat cancer and ischemia, whereas HIF activators could be utilized for stroke and spinal cord injuries. Significant developments have been made towards understanding the roles of the HIFs under both physiological and pathophysiological conditions. The roles of $\operatorname{HIF}(s)$ are becoming clearer during physiological adaptation. The interaction of HIF- $1 \alpha$ with HIF- $2 \alpha$ and HIF- $3 \alpha$ during physiological adaptation will provide a great deal of understanding of HIF(s). Moreover how these transcription factors interact with other known proteins and pathways will help in designing the future therapeutics with minimal side effect.

\section{Conflict of Interests}

The authors declare that there is no conflict of interests regarding the publication of this paper.

\section{Acknowledgment}

This work was supported by the National Research Foundation of Korea (NRF) Grant funded by the Korea government (MEST) (no. 2014R1A2A2A04007791).

\section{References}

[1] H. Tian, S. L. McKnight, and D. W. Russell, "Endothelial PAS domain protein 1 (EPAS1), a transcription factor selectively expressed in endothelial cells," Genes \& Development, vol. 11, no. 1, pp. 72-82, 1997.

[2] M. Ema, S. Taya, N. Yokotani, K. Sogawa, Y. Matsuda, and Y. Fujii-Kuriyama, "A novel bHLH-PAS factor with close sequence similarity to hypoxia-inducible factor $1 \alpha$ regulates the VEGF expression and is potentially involved in lung and vascular development," Proceedings of the National Academy of Sciences of the United States of America, vol. 94, no. 9, pp. 4273-4278, 1997.

[3] Y. Z. Gu, S. M. Moran, J. B. Hogenesch, L. Wartman, and C. A. Bradfield, "Molecular characterization and chromosomal localization of a third alpha-class hypoxia inducible factor subunit, HIF3alpha," Gene Expression, vol. 7, no. 3, pp. 205-213, 1998.
[4] G. L. Semenza, "Regulation of mammalian $\mathrm{O}_{2}$ homeostasis by hypoxia-inducible factor 1," Annual Review of Cell and Developmental Biology, vol. 15, pp. 551-578, 1999.

[5] L. E. Eric Huang, E. A. Pete, M. Schau, J. Milligan, and J. $\mathrm{Gu}$, "Leu-574 of HIF- $1 \alpha$ is essential for the von Hippel-Lindau (VHL)-mediated degradation pathway," The Journal of Biological Chemistry, vol. 277, no. 44, pp. 41750-41755, 2002.

[6] Y. Kageyama, M. Koshiji, K. K. W. To, Y.-M. Tian, P. J. Ratcliffe, and L. E. Huang, "Leu-574 of human HIF-1 $\alpha$ is a molecular determinant of prolyl hydroxylation," The FASEB Journal, vol. 18, no. 9, pp. 1028-1030, 2004.

[7] N. Masson, C. Willam, P. H. Maxwell, C. W. Pugh, and P. J. Ratcliffe, "Independent function of two destruction domains in hypoxia-inducible factor-alpha chains activated by prolyl hydroxylation," The EMBO Journal, vol. 20, no. 18, pp. 51975206, 2001.

[8] M. C. Simon and B. Keith, "The role of oxygen availability in embryonic development and stem cell function," Nature Reviews Molecular Cell Biology, vol. 9, no. 4, pp. 285-296, 2008.

[9] P. J. Kallio, K. Okamoto, S. O’Brien et al., "Signal transduction in hypoxic cells: inducible nuclear translocation and recruitment of the CBP/p300 coactivator by the hypoxia-inducible factorlalpha," The EMBO Journal, vol. 17, no. 22, pp. 6573-6586, 1998.

[10] C. W. Pugh, J. F. O’Rourke, M. Nagao, J. M. Gleadle, and P. J. Ratcliffe, "Activation of hypoxia-inducible factor-1; Definition of regulatory domains within the $\alpha$ subunit," The Journal of Biological Chemistry, vol. 272, no. 17, pp. 11205-11214, 1997.

[11] R. Fukuda, H. Zhang, J. W. Kim, L. Shimoda, C. V. Dang, and G. Semenza, "HIF-1 regulates cytochrome oxidase subunits to optimize efficiency of respiration in hypoxic cells," Cell, vol. 129, no. 1, pp. 111-122, 2007.

[12] C. Warnecke, Z. Zaborowska, J. Kurreck et al., "Differentiating the functional role of hypoxia-inducible factor (HIF)- $1 \alpha$ and HIF- $2 \alpha$ (EPAS-1) by the use of RNA interference: erythropoietin is a HIF- $2 \alpha$ target gene in Hep3B and Kelly cells," The FASEB Journal, vol. 18, no. 12, pp. 1462-1464, 2004.

[13] C.-J. Hu, L.-Y. Wang, L. A. Chodosh, B. Keith, and M. C. Simon, "Differential Roles of Hypoxia-Inducible Factor $1 \alpha$ (HIF-1 $\alpha$ ) and HIF- $2 \alpha$ in Hypoxic Gene Regulation," Molecular and Cellular Biology, vol. 23, no. 24, pp. 9361-9374, 2003.

[14] R. R. Raval, K. W. Lau, M. G. B. Tran et al., "Contrasting properties of hypoxia-inducible factor 1 (HIF-1) and HIF-2 in von Hippel-Lindau-associated renal cell carcinoma," Molecular and Cellular Biology, vol. 25, no. 13, pp. 5675-5686, 2005.

[15] G. P. Elvidge, L. Glenny, R. J. Appelhoff, P. J. Ratcliffe, J. Ragoussis, and J. M. Gleadle, "Concordant regulation of gene expression by hypoxia and 2-oxoglutarate-dependent dioxygenase inhibition: the role of HIF- $1 \alpha$, HIF- $2 \alpha$, and other pathways," The Journal of Biological Chemistry, vol. 281, no. 22, pp. 15215-15226, 2006.

[16] M. Heidbreder, F. Fröhlich, O. Jöhren, A. Dendorfer, F. Qadri, and P. Dominiak, "Hypoxia rapidly activates HIF-3alpha mRNA expression," The FASEB Journal, vol. 17, no. 11, pp. 1541-1543, 2003.

[17] P. Zhang, L. Lu, Q. Yao et al., "Molecular, functional, and gene expression analysis of zebrafish hypoxia-inducible factor3alpha," The American Journal of Physiology-Regulatory Integrative and Comparative Physiology, vol. 303, no. 11, pp. R1165R1174, 2012.

[18] Y. Makino, A. Kanopka, W. J. Wilson, H. Tanaka, and L. Poellinger, "Inhibitory PAS domain protein (IPAS) is a hypoxiainducible splicing variant of the hypoxia-inducible factor- $3 \alpha$ 
locus," The Journal of Biological Chemistry, vol. 277, no. 36, pp. 32405-32408, 2002.

[19] L. Holmquist-Mengelbier, E. Fredlund, T. Löfstedt et al., "Recruitment of HIF- $1 \alpha$ and HIF- $2 \alpha$ to common target genes is differentially regulated in neuroblastoma: HIF- $2 \alpha$ promotes an aggressive phenotype," Cancer Cell, vol. 10, no. 5, pp. 413-423, 2006.

[20] M. Y. Koh, R. Lemos Jr., X. Liu, and G. Powis, "The hypoxia-associated factor switches cells from HIF-1 $\alpha$ - to HIF$2 \alpha$-dependent signaling promoting stem cell characteristics, aggressive tumor growth and invasion," Cancer Research, vol. 71, no. 11, pp. 4015-4027, 2011.

[21] P. Jaakkola, D. R. Mole, Y.-M. Tian et al., “Targeting of HIF- $\alpha$ to the von Hippel-Lindau ubiquitylation complex by $\mathrm{O}_{2}$-regulated prolyl hydroxylation," Science, vol. 292, no. 5516, pp. 468-472, 2001.

[22] M. Ivan, K. Kondo, H. Yang et al., "HIF $\alpha$ targeted for VHLmediated destruction by proline hydroxylation: implications for $\mathrm{O}_{2}$ sensing," Science, vol. 292, no. 5516, pp. 464-468, 2001.

[23] L. E. Huang, J. Gu, M. Schau, and H. F. Bunn, "Regulation of hypoxia-inducible factor $1 \alpha$ is mediated by an $\mathrm{O}_{2}$-dependent degradation domain via the ubiquitin-proteasome pathway," Proceedings of the National Academy of Sciences of the United States of America, vol. 95, no. 14, pp. 7987-7992, 1998.

[24] A. C. R. Epstein, J. M. Gleadle, L. A. McNeill et al., " $C$. elegans EGL-9 and mammalian homologs define a family of dioxygenases that regulate HIF by prolyl hydroxylation," Cell, vol. 107, no. 1, pp. 43-54, 2001.

[25] E. Berra, E. Benizri, A. Ginouvès, V. Volmat, D. Roux, and J. Pouysségur, "HIF prolyl-hydroxylase 2 is the key oxygen sensor setting low steady-state levels of HIF- $1 \alpha$ in normoxia," The EMBO Journal, vol. 22, no. 16, pp. 4082-4090, 2003.

[26] K. Lee, H. Zhang, D. Z. Qian, S. Rey, J. O. Liu, and G. L. Semenza, "Acriflavine inhibits HIF-1 dimerization, tumor growth, and vascularization," Proceedings of the National Academy of Sciences of the United States of America, vol. 106, no. 42, pp. 17910-17915, 2009.

[27] R. Chowdhury, M. A. McDonough, J. Mecinović et al., "Structural basis for binding of hypoxia-inducible factor to the oxygen-sensing prolyl hydroxylases," Structure, vol. 17, no. 7, pp. 981-989, 2009.

[28] M. E. Lieb, K. Menzies, M. C. Moschella, R. Ni, and M. B. Taubman, "Mammalian EGLN genes have distinct patterns of mRNA expression and regulation," Biochemistry and Cell Biology, vol. 80, no. 4, pp. 421-426, 2002.

[29] J. Aragonés, M. Schneider, K. van Geyte et al., "Deficiency or inhibition of oxygen sensor Phd1 induces hypoxia tolerance by reprogramming basal metabolism," Nature Genetics, vol. 40, no. 2, pp. 170-180, 2008.

[30] M. Schneider, K. van Geyte, P. Fraisl et al., "Loss or silencing of the PHD1 prolyl hydroxylase protects livers of mice against ischemia/reperfusion injury," Gastroenterology, vol. 138, no. 3, pp. 1143.e2-1154.e2, 2010.

[31] K. Takeda, V. C. Ho, H. Takeda, L.-J. Duan, A. Nagy, and G.H. Fong, "Placental but not heart defects are associated with elevated hypoxia-inducible factor alpha levels in mice lacking prolyl hydroxylase domain protein 2," Molecular and Cellular Biology, vol. 26, no. 22, pp. 8336-8346, 2006.

[32] K. Takeda, A. Cowan, and G.-H. Fong, "Essential role for prolyl hydroxylase domain protein 2 in oxygen homeostasis of the adult vascular system," Circulation, vol. 116, no. 7, pp. 774-781, 2007.
[33] Y. A. Minamishima, J. Moslehi, N. Bardeesy, D. Cullen, R. T. Bronson, and W. G. Kaelin Jr., "Somatic inactivation of the PHD2 prolyl hydroxylase causes polycythemia and congestive heart failure," Blood, vol. 111, no. 6, pp. 3236-3244, 2008.

[34] T. Bishop, D. Gallagher, A. Pascual et al., "Abnormal sympathoadrenal development and systemic hypotension in $\mathrm{PHD}^{-/-}$ mice," Molecular and Cellular Biology, vol. 28, no. 10, pp. 33863400, 2008.

[35] B. Oriowo, M. Thirunavukkarasu, V. Selvaraju et al., “Targeted gene deletion of prolyl hydroxylase domain protein 3 triggers angiogenesis and preserves cardiac function by stabilizing hypoxia inducible factor 1 alpha following myocardial infarction," Current Pharmaceutical Design, vol. 20, no. 9, pp. 13051310, 2014.

[36] B. M. Babior, "The NADPH oxidase of endothelial cells," IUBMB Life, vol. 50, no. 4-5, pp. 267-269, 2000.

[37] B. M. Babior, J. D. Lambeth, and W. Nauseef, "The neutrophil NADPH oxidase," Archives of Biochemistry and Biophysics, vol. 397, no. 2, pp. 342-344, 2002.

[38] M. J. Coon, X. Ding, S. J. Pernecky, and A. D. N. Vaz, "Cytochrome P450: progress and predictions," The FASEB Journal, vol. 6, no. 2, pp. 669-673, 1992.

[39] Y. Yokoyama, J. S. Beckman, T. K. Beckman et al., "Circulating xanthine oxidase: potential mediator of ischemic injury," American Journal of Physiology-Gastrointestinal and Liver Physiology, vol. 258, no. 4, pp. G564-G570, 1990.

[40] J. F. Turrens, "Superoxide production by the mitochondrial respiratory chain," Bioscience Reports, vol. 17, no. 1, pp. 3-8, 1997.

[41] M. L. Genova, B. Ventura, G. Giuliano et al., "The site of production of superoxide radical in mitochondrial Complex I is not a bound ubisemiquinone but presumably iron-sulfur cluster N2," FEBS Letters, vol. 505, no. 3, pp. 364-368, 2001.

[42] S. Alvarez, L. B. Valdez, T. Zaobornyj, and A. Boveris, "Oxygen dependence of mitochondrial nitric oxide synthase activity," Biochemical and Biophysical Research Communications, vol. 305, no. 3, pp. 771-775, 2003.

[43] G. B. Waypa and P. T. Schumacker, "O${ }_{2}$ sensing in hypoxic pulmonary vasoconstriction: the mitochondrial door re-opens," Respiratory Physiology and Neurobiology, vol. 132, no. 1, pp. 8191, 2002.

[44] P. T. Schumacker, "Hypoxia, anoxia, and $\mathrm{O}_{2}$ sensing: the search continues," The American Journal of Physiology-Lung Cellular and Molecular Physiology, vol. 283, no. 5, pp. L918-L921, 2002.

[45] N. S. Chandel, E. Maltepe, E. Goldwasser, C. E. Mathieu, M. C. Simon, and P. T. Schumacker, "Mitochondrial reactive oxygen species trigger hypoxia-induced transcription," Proceedings of the National Academy of Sciences of the United States of America, vol. 95, no. 20, pp. 11715-11720, 1998.

[46] C. Schroedl, D. S. McClintock, G. R. S. Budinger, and N. S. Chandel, "Hypoxic but not anoxic stabilization of HIF- $1 \alpha$ requires mitochondrial reactive oxygen species," The American Journal of Physiology - Lung Cellular and Molecular Physiology, vol. 283, no. 5, pp. L922-L931, 2002.

[47] F. H. Agani, P. Pichiule, J. C. Chavez, and J. C. LaManna, "The role of mitochondria in the regulation of hypoxia-inducible factor 1 expression during hypoxia," The Journal of Biological Chemistry, vol. 275, no. 46, pp. 35863-35867, 2000.

[48] H. Kumar, H. W. Lim, S. V. More et al., “The role of free radicals in the aging brain and Parkinson's disease: convergence and parallelism," International Journal of Molecular Sciences, vol. 13, no. 8, pp. 10478-10504, 2012. 
[49] L. D. Lukyanova, "Mitochondrial signaling in hypoxia," Open Journal of Endocrine and Metabolic Diseases, vol. 3, no. 2, pp. 20-32, 2013.

[50] K. D. Mansfield, R. D. Guzy, Y. Pan et al., "Mitochondrial dysfunction resulting from loss of cytochrome c impairs cellular oxygen sensing and hypoxic HIF- $\alpha$ activation," Cell Metabolism, vol. 1, no. 6, pp. 393-399, 2005.

[51] R. D. Guzy, B. Hoyos, E. Robin et al., "Mitochondrial complex III is required for hypoxia-induced ROS production and cellular oxygen sensing," Cell Metabolism, vol. 1, no. 6, pp. 401-408, 2005.

[52] N. S. Chandel, D. S. McClintock, C. E. Feliciano et al., "Reactive oxygen species generated at mitochondrial Complex III stabilize hypoxia-inducible factor- $1 \alpha$ during hypoxia: a mechanism of $\mathrm{O}_{2}$ sensing," The Journal of Biological Chemistry, vol. 275, no. 33, pp. 25130-25138, 2000.

[53] E. L. Bell, T. A. Klimova, J. Eisenbart et al., "The $Q_{o}$ site of the mitochondrial complex III is required for the transduction of hypoxic signaling via reactive oxygen species production," The Journal of Cell Biology, vol. 177, no. 6, pp. 1029-1036, 2007.

[54] D. E. Richard, E. Berra, and J. Pouyssegur, "Nonhypoxic pathway mediates the induction of hypoxia-inducible factor $1 \alpha$ in vascular smooth muscle cells," The Journal of Biological Chemistry, vol. 275, no. 35, pp. 26765-26771, 2000.

[55] L. E. Kotch, N. V. Iyer, E. Laughner, and G. L. Semenza, "Defective vascularization of HIF-1 $\alpha$-null embryos is not associated with VEGF deficiency but with mesenchymal cell death," Developmental Biology, vol. 209, no. 2, pp. 254-267, 1999.

[56] H. Tian, R. E. Hammer, A. M. Matsumoto, D. W. Russell, and S. L. McKnight, "The hypoxia-responsive transcription factor EPAS1 is essential for catecholamine homeostasis and protection against heart failure during embryonic development," Genes and Development, vol. 12, no. 21, pp. 3320-3324, 1998.

[57] D. M. Stroka, T. Burkhardt, I. Desbaillets et al., "HIF-1 is expressed in normoxic tissue and displays an organ-specific regulation under systemic hypoxia," The FASEB Journal, vol. 15, no. 13, pp. 2445-2453, 2001.

[58] J. Peng, L. Zhang, L. Drysdale, and G.-H. Fong, "The transcription factor EPAS-1/hypoxia-inducible factor $2 \alpha$ plays an important role in vascular remodeling," Proceedings of the National Academy of Sciences of the United States of America, vol. 97, no. 15, pp. 8386-8391, 2000.

[59] K. Brusselmans, F. Bono, P. Maxwell et al., "Hypoxia-inducible factor- $2 \alpha$ (HIF- $2 \alpha$ ) is involved in the apoptotic response to hypoglycemia but not to hypoxia," The Journal of Biological Chemistry, vol. 276, no. 42, pp. 39192-39196, 2001.

[60] D. Chilov, T. Hofer, C. Bauer, R. H. Wenger, and M. Gassmann, "Hypoxia affects expression of circadian genes PER1 and CLOCK in mouse brain," The FASEB Journal, vol. 15, no. 14, pp. 2613-2622, 2001.

[61] H. H. Marti, D. M. Katschinski, K. F. Wagner, L. Schäffer, B. Stier, and R. H. Wenger, "Isoform-specific expression of hypoxia-inducible factor-lalpha during the late stages of mouse spermiogenesis," Molecular Endocrinology, vol. 16, no. 2, pp. 234-243, 2002.

[62] D. Lukashev, C. Caldwell, A. Ohta, P. Chen, and M. Sitkovsky, "Differential Regulation of two alternatively spliced isoforms of hypoxia-inducible factor-lalpha in activated T lymphocytes," The Journal of Biological Chemistry, vol. 276, no. 52, pp. 4875448763, 2001.

[63] D. M. Katschinski, L. Le, D. Heinrich et al., "Heat induction of the unphosphorylated form of hypoxia-inducible factor-1alpha is dependent on heat shock protein-90 activity," Journal of Biological Chemistry, vol. 277, no. 11, pp. 9262-9267, 2002.

[64] R. Lall, S. Ganapathy, M. Yang et al., "Low-dose radiation exposure induces a HIF-1-mediated adaptive and protective metabolic response," Cell Death and Differentiation, vol. 21, no. 5, pp. 836-844, 2014.

[65] S. Carrera, J. Senra, M. I. Acosta et al., "The role of the HIF-1 $\alpha$ transcription factor in increased cell division at physiological oxygen tensions," PLoS ONE, vol. 9, no. 5, Article ID e97938, 2014.

[66] C.-H. Kim, Y.-S. Cho, Y.-S. Chun, J.-W. Park, and M.-S. Kim, "Early expression of myocardial HIF-1 $\alpha$ in response to mechanical stresses: regulation by stretch-activated channels and the phosphatidylinositol 3-kinase signaling pathway," Circulation Research, vol. 90, no. 2, pp. e25-e33, 2002.

[67] N. V. Iyer, L. E. Kotch, F. Agani et al., "Cellular and developmental control of $\mathrm{O}_{2}$ homeostasis by hypoxia-inducible factor $1 \alpha$," Genes and Development, vol. 12, no. 2, pp. 149-162, 1998.

[68] H. E. Ryan, J. Lo, and R. S. Johnson, "HIF-1 $\alpha$ is required for solid tumor formation and embryonic vascularization," The EMBO Journal, vol. 17, no. 11, pp. 3005-3015, 1998.

[69] E. J. Folco, G. K. Sukhova, T. Quillard, and P. Libby, "Moderate hypoxia potentiates interleukin-1beta production in activated human macrophages," Circulation Research, vol. 115, no. 10, pp. 875-883, 2014.

[70] A. Y. Yu, L. A. Shimoda, N. V. Iyer et al., "Impaired physiological responses to chronic hypoxia in mice partially deficient for hypoxia-inducible factor $1 \alpha$," The Journal of Clinical Investigation, vol. 103, no. 5, pp. 691-696, 1999.

[71] L. A. Shimoda, D. J. Manalo, J. S. K. Sham, G. L. Semenza, and J. T. Sylvester, "Partial HIF-1 $\alpha$ deficiency impairs pulmonary arterial myocyte electrophysiological responses to hypoxia," The American Journal of Physiology-Lung Cellular and Molecular Physiology, vol. 281, no. 1, pp. L202-L208, 2001.

[72] J.-C. Roux, H. Brismar, A. Aperia, and H. Lagercrantz, "Developmental changes in HIF transcription factor in carotid body: relevance for $\mathrm{O}_{2}$ sensing by chemoreceptors," Pediatric Research, vol. 58, no. 1, pp. 53-57, 2005.

[73] D. D. Kline, Y.-J. Peng, D. J. Manalo, G. L. Semenza, and N. R. Prabhakar, "Defective carotid body function and impaired ventilatory responses to chronic hypoxia in mice partially deficient for hypoxia-inducible factor $1 \alpha$," Proceedings of the National Academy of Sciences of the United States of America, vol. 99, no. 2, pp. 821-826, 2002.

[74] Y.-J. Peng, J. Nanduri, S. A. Khan et al., "Hypoxia-inducible factor $2 \alpha$ (HIF-2 $\alpha$ ) heterozygous-null mice exhibit exaggerated carotid body sensitivity to hypoxia, breathing instability, and hypertension," Proceedings of the National Academy of Sciences of the United States of America, vol. 108, no. 7, pp. 3065-3070, 2011.

[75] G. Yuan, Y.-J. Peng, V. D. Reddy et al., "Mutual antagonism between hypoxia-inducible factors $1 \alpha$ and $2 \alpha$ regulates oxygen sensing and cardio-respiratory homeostasis," Proceedings of the National Academy of Sciences of the United States of America, vol. 110, no. 19, pp. E1788-E1796, 2013.

[76] E. Schipani, H. E. Ryan, S. Didrickson, T. Kobayashi, M. Knight, and R. S. Johnson, "Hypoxia in cartilage: HIF-1 $\alpha$ is essential for chondrocyte growth arrest and survival," Genes \& Development, vol. 15, no. 21, pp. 2865-2876, 2001.

[77] O. Genbacev, Y. Zhou, J. W. Ludlow, and S. J. Fisher, "Regulation of human placental development by oxygen tension," Science, vol. 277, no. 5332, pp. 1669-1672, 1997. 
[78] D. M. Adelman, M. Gertsenstein, A. Nagy, M. C. Simon, and E. Maltepe, "Placental cell fates are regulated in vivo by HIFmediated hypoxia responses," Genes and Development, vol. 14, no. 24, pp. 3191-3203, 2000.

[79] E. Maltepe, G. W. Krampitz, K. M. Okazaki et al., "Hypoxiainducible factor-dependent histone deacetylase activity determines stem cell fate in the placenta," Development, vol. 132, no. 15, pp. 3393-3403, 2005.

[80] I. Caniggia, H. Mostachfi, J. Winter et al., "Hypoxia-inducible factor-1 mediates the biological effects of oxygen on human trophoblast differentiation through TGF $\beta 3$," Journal of Clinical Investigation, vol. 105, no. 5, pp. 577-587, 2000.

[81] A. Scheid, R. H. Wenger, L. Schäffer et al., "Physiologically low oxygen concentrations in fetal skin regulate hypoxia-inducible factor 1 and transforming growth factor-beta3," The FASEB Journal, vol. 16, no. 3, pp. 411-413, 2002.

[82] E. B. Rankin, A. J. Giaccia, and E. Schipani, "A central role for hypoxic signaling in cartilage, bone, and hematopoiesis," Current Osteoporosis Reports, vol. 9, no. 2, pp. 46-52, 2011.

[83] E. Duval, S. Leclercq, J.-M. Elissalde, M. Demoor, P. Galéra, and K. Boumédiene, "Hypoxia-inducible factor lalpha inhibits the fibroblast-like markers type I and type III collagen during hypoxia-induced chondrocyte redifferentiation: hypoxia not only induces type II collagen and aggrecan, but it also inhibits type I and type III collagen in the hypoxia-inducible factor lalpha-dependent redifferentiation of chondrocytes," Arthritis and Rheumatism, vol. 60, no. 10, pp. 3038-3048, 2009.

[84] J. Bohensky, I. M. Shapiro, S. Leshinsky, S. P. Terkhorn, C. S. Adams, and V. Srinivas, "HIF-1 regulation of chondrocyte apoptosis: induction of the autophagic pathway," Autophagy, vol. 3, no. 3, pp. 207-214, 2007.

[85] T. Saito, A. Fukai, A. Mabuchi et al., "Transcriptional regulation of endochondral ossification by HIF- $2 \alpha$ during skeletal growth and osteoarthritis development," Nature Medicine, vol. 16, no. 6, pp. 678-686, 2010.

[86] S. Yang, J. Kim, J. H. Ryu et al., "Hypoxia-inducible factor2alpha is a catabolic regulator of osteoarthritic cartilage destruction," Nature Medicine, vol. 16, no. 6, pp. 687-693, 2010.

[87] I. Papandreou, R. A. Cairns, L. Fontana, A. L. Lim, and N. C. Denko, "HIF-1 mediates adaptation to hypoxia by actively downregulating mitochondrial oxygen consumption," Cell Metabolism, vol. 3, no. 3, pp. 187-197, 2006.

[88] T. Tsukihara, H. Aoyama, E. Yamashita et al., "The whole structure of the 13-subunit oxidized cytochrome $c$ oxidase at 2.8 Å," Science, vol. 272, no. 5265, pp. 1136-1144, 1996.

[89] L. G. J. Nijtmans, J.-W. Taanman, A. O. Muijsers, D. Speijer, and C. van den Bogert, "Assembly of cytochrome-c oxidase in cultured human cells," European Journal of Biochemistry, vol. 254, no. 2, pp. 389-394, 1998.

[90] J. Napiwotzki and B. Kadenbach, "Extramitochondrial ATP/ADP-ratios regulate cytochrome $c$ oxidase activity via binding to the cytosolic domain of subunit IV," Biological Chemistry, vol. 379, no. 3, pp. 335-339, 1998.

[91] H. Zhang, M. Bosch-Marce, L. A. Shimoda et al., "Mitochondrial autophagy is an HIF-1-dependent adaptive metabolic response to hypoxia," Journal of Biological Chemistry, vol. 283, no. 16, pp. 10892-10903, 2008.

[92] R. A. Menzies and P. H. Gold, "The turnover of mitochondria in a variety of tissues of young adult and aged rats," The Journal of Biological Chemistry, vol. 246, no. 8, pp. 2425-2429, 1971.
[93] B. Levine and D. J. Klionsky, "Development by self-digestion: molecular mechanisms and biological functions of autophagy," Developmental Cell, vol. 6, no. 4, pp. 463-477, 2004.

[94] M. Kundu and C. B. Thompson, "Macroautophagy versus mitochondrial autophagy: a question of fate?" Cell Death \& Differentiation, vol. 12, supplement 2, pp. 1484-1489, 2005.

[95] C. de Duve and R. Wattiaux, "Functions of lysosomes," Annual Review of Physiology, vol. 28, pp. 435-492, 1966.

[96] H. Zhu, P. Tannous, J. L. Johnstone et al., "Cardiac autophagy is a maladaptive response to hemodynamic stress," The Journal of Clinical Investigation, vol. 117, no. 7, pp. 1782-1793, 2007.

[97] R. S. Decker and K. Wildenthal, "Lysosomal alterations in hypoxic and reoxygenated hearts. I. Ultrastructural and cytochemical changes," The American Journal of Pathology, vol. 98, no. 2, pp. 425-444, 1980.

[98] A. Hamacher-Brady, N. R. Brady, S. E. Logue et al., "Response to myocardial ischemia/reperfusion injury involves Bnip3 and autophagy," Cell Death \& Differentiation, vol. 14, no. 1, pp. 146157, 2007.

[99] R. K. Bruick, "Expression of the gene encoding the proapoptotic Nip3 protein is induced by hypoxia," Proceedings of the National Academy of Sciences of the United States of America, vol. 97, no. 16, pp. 9082-9087, 2000.

[100] D. Feldser, F. Agani, N. V. Iyer, B. Pak, G. Ferreira, and G. L. Semenza, "Reciprocal positive regulation of hypoxia-inducible factor lalpha and insulin-like growth factor 2," Cancer Research, vol. 59, no. 16, pp. 3915-3918, 1999.

[101] M. C. Maiuri, G. Le Toumelin, A. Criollo et al., "Functional and physical interaction between $\mathrm{Bcl}-\mathrm{X}_{L}$ and a $\mathrm{BH} 3$-like domain in Beclin-1," The EMBO Journal, vol. 26, no. 10, pp. 2527-2539, 2007.

[102] P. C. Fernandez, S. R. Frank, L. Wang et al., "Genomic targets of the human c-Myc protein," Genes and Development, vol. 17, no. 9, pp. 1115-1129, 2003.

[103] Z. Li, S. van Calcar, C. Qu, W. K. Cavenee, M. Q. Zhang, and B. Ren, "A global transcriptional regulatory role for c-Myc in Burkitt's lymphoma cells," Proceedings of the National Academy of Sciences of the United States of America, vol. 100, no. 14, pp. 8164-8169, 2003.

[104] H. Zhang, P. Gao, R. Fukuda et al., "HIF-1 inhibits mitochondrial biogenesis and cellular respiration in VHL-deficient renal cell carcinoma by repression of C-MYC activity," Cancer Cell, vol. 11, no. 5, pp. 407-420, 2007.

[105] J. D. Gordan, C. B. Thompson, and M. C. Simon, "HIF and cMyc: sibling rivals for control of cancer cell metabolism and proliferation," Cancer Cell, vol. 12, no. 2, pp. 108-113, 2007.

[106] C. V. Dang, J.-W. Kim, P. Gao, and J. Yustein, “The interplay between MYC and HIF in cancer," Nature Reviews Cancer, vol. 8, no. 1, pp. 51-56, 2008.

[107] P. Carmeliet, Y. Dor, J. M. Herbert et al., "Role of HIF-1alpha in hypoxia-mediated apoptosis, cell proliferation and tumour angiogenesis," Nature, vol. 394, pp. 485-490, 1998.

[108] N. Akakura, M. Kobayashi, I. Horiuchi et al., "Constitutive expression of hypoxia-inducible factor-l $\alpha$ renders pancreatic cancer cells resistant to apoptosis induced by hypoxia and nutrient deprivation," Cancer Research, vol. 61, no. 17, pp. 65486554, 2001.

[109] M. T. Santore, D. S. McClintock, V. Y. Lee, G. R. S. Budinger, and N. S. Chandel, "Anoxia-induced apoptosis occurs through a mitochondria-dependent pathway in lung epithelial cells," American Journal of Physiology -Lung Cellular and Molecular Physiology, vol. 282, no. 4, pp. L727-L734, 2002. 
[110] D. S. McClintock, M. T. Santore, V. Y. Lee et al., "Bc1-2 family members and functional electron transport chain regulate oxygen deprivation-induced cell death," Molecular and Cellular Biology, vol. 22, no. 1, pp. 94-104, 2002.

[111] P. Saikumar, Z. Dong, Y. Patel et al., "Role of hypoxia-induced Bax translocation and cytochrome c release in reoxygenation injury," Oncogene, vol. 17, no. 26, pp. 3401-3415, 1998.

[112] M. C. Wei, W. X. Zong, E. H. Y. Cheng et al., "Proapoptotic BAX and BAK: a requisite gateway to mitochondrial dysfunction and death," Science, vol. 292, no. 5517, pp. 727-730, 2001.

[113] S. Shimizu, Y. Eguchi, H. Kosaka, W. Kamiike, H. Matsuda, and Y. Tsujimoto, "Prevention of hypoxia-induced cell death by Bcl2 and Bcl-xL," Nature, vol. 374, no. 6525, pp. 811-813, 1995.

[114] T. G. Graeber, C. Osmanian, T. Jacks et al., "Hypoxia-mediated selection of cells with diminished apoptotic potential in solid tumours," Nature, vol. 379, pp. 88-91, 1996.

[115] N. Morishima, K. Nakanishi, H. Takenouchi, T. Shibata, and Y. Yasuhiko, "An endoplasmic reticulum stress-specific caspase cascade in apoptosis. Cytochrome $c$-independent activation of caspase- 9 by caspase-12," The Journal of Biological Chemistry, vol. 277, no. 37, pp. 34287-34294, 2002.

[116] S. Basu and R. Kolesnick, "Stress signals for apoptosis: ceramide and c-Jun kinase," Oncogene, vol. 17, no. 25, pp. 3277-3285, 1998.

[117] A. Giatromanolaki, E. Sivridis, C. Kouskoukis, K. C. Gatter, A. L. Harris, and M. I. Koukourakis, "Hypoxia-inducible factors $1 \alpha$ and $2 \alpha$ are related to vascular endothelial growth factor expression and a poorer prognosis in nodular malignant melanomas of the skin," Melanoma Research, vol. 13, no. 5, pp. 493-501, 2003.

[118] S. C. Hanna, B. Krishnan, S. T. Bailey et al., "HIF1 $\alpha$ and HIF2 $\alpha$ independently activate SRC to promote melanoma metastases," Journal of Clinical Investigation, vol. 123, no. 5, pp. 2078-2093, 2013.

[119] V. Barak, J. Pe'er, I. Kalickman, and S. Frenkel, "VEGF as a biomarker for metastatic uveal melanoma in humans," Current Eye Research, vol. 36, no. 4, pp. 386-390, 2011.

[120] A. Giatromanolaki, E. Sivridis, C. Simopoulos et al., "Hypoxia inducible factors lalpha and 2alpha are associated with VEGF expression and angiogenesis in gallbladder carcinomas," Journal of Surgical Oncology, vol. 94, no. 3, pp. 242-247, 2006.

[121] M. Baba, S. Hirai, H. Yamada-Okabe et al., "Loss of von HippelLindau protein causes cell density dependent deregulation of CyclinD1 expression through Hypoxia-inducible factor," Oncogene, vol. 22, no. 18, pp. 2728-2738, 2003.

[122] M. Koshiji, Y. Kageyama, E. A. Pete, I. Horikawa, J. C. Barrett, and L. E. Huang, "HIF-1 $\alpha$ induces cell cycle arrest by functionally counteracting Myc," The EMBO Journal, vol. 23, no. 9, pp. 1949-1956, 2004.

[123] R. A. Kauppinen and S. R. Williams, "Cerebral energy metabolism and intracellular $\mathrm{pH}$ during severe hypoxia and recovery: a study using ${ }^{1} \mathrm{H},{ }^{31} \mathrm{P}$, and ${ }^{1} \mathrm{H}\left[{ }^{13} \mathrm{C}\right]$ nuclear magnetic resonance spectroscopy in the guinea pig cerebral cortex in vitro," Journal of Neuroscience Research, vol. 26, no. 3, pp. 356369, 1990.

[124] M. V. Cutaia, N. Parks, J. Centracchio, S. Rounds, K. P. Yip, and A. M. Sun, "Effect of hypoxic exposure on $\mathrm{Na}+\mathrm{H}+$ antiport activity, isoform expression, and localization in endothelial cells," American Journal of Physiology: Lung Cellular and Molecular Physiology, vol. 275, no. 3, pp. L442-L451, 1998.

[125] L. K. Putney, S. P. Denker, and D. L. Barber, "The changing face of the $\mathrm{Na}^{+} / \mathrm{H}+$ exchanger, NHE1: structure, regulation, and cellular actions," Annual Review of Pharmacology and Toxicology, vol. 42, pp. 527-552, 2002.
[126] D. A. Quinn, C. G. W. Dahlberg, J. P. Bonventre et al., “The role of $\mathrm{Na}+\mathrm{H}+$ exchange and growth factors in pulmonary artery smooth muscle cell proliferation," The American Journal of Respiratory Cell and Molecular Biology, vol. 14, no. 2, pp. 139145, 1996.

[127] R. M. Leach, D. W. Sheehan, V. P. Chacko, and J. T. Sylvester, "Effects of hypoxia on energy state and $\mathrm{pH}$ in resting pulmonary and femoral arterial smooth muscles," The American Journal of Physiology_Lung Cellular and Molecular Physiology, vol. 275, no. 6, pp. L1051-L1060, 1998.

[128] R. M. Leach, D. W. Sheehan, V. P. Chacko, and J. T. Sylvester, "Energy state, $\mathrm{pH}$, and vasomotor tone during hypoxia in precontracted pulmonary and femoral arteries," The American Journal of Physiology - Lung Cellular and Molecular Physiology, vol. 278, no. 2, pp. L294-L304, 2000.

[129] E. J. Rios, M. Fallon, J. Wang, and L. A. Shimoda, "Chronic hypoxia elevates intracellular $\mathrm{pH}$ and activates $\mathrm{Na}^{+} / \mathrm{H}^{+}$ exchange in pulmonary arterial smooth muscle cells," American Journal of Physiology_Lung Cellular and Molecular Physiology, vol. 289, no. 5, pp. L867-L874, 2005.

[130] L. A. Shimoda, M. Fallon, S. Pisarcik, J. Wang, and G. L. Semenza, "HIF-1 regulates hypoxic induction of NHE1 expression and alkalinization of intracellular $\mathrm{pH}$ in pulmonary arterial myocytes," American Journal of Physiology: Lung Cellular and Molecular Physiology, vol. 291, no. 5, pp. L941-L949, 2006.

[131] H.-Y. Sun, N.-P. Wang, M. E. Halkos et al., "Involvement of $\mathrm{Na}^{+} / \mathrm{H}^{+}$exchanger in hypoxia/re-oxygenation-induced neonatal rat cardiomyocyte apoptosis," European Journal of Pharmacology, vol. 486, no. 2, pp. 121-131, 2004.

[132] M. Stubbs, P. M. J. McSheehy, J. R. Griffiths, and C. L. Bashford, "Causes and consequences of tumour acidity and implications for treatment," Molecular Medicine Today, vol. 6, no. 1, pp. 15-19, 2000.

[133] D. Fukumura, L. Xu, Y. Chen, T. Gohongi, B. Seed, and R. K. Jain, "Hypoxia and acidosis independently up-regulate vascular endothelial growth factor transcription in brain tumors in vivo," Cancer Research, vol. 61, no. 16, pp. 6020-6024, 2001.

[134] E. Švastová, A. Hulíková, M. Rafajová et al., "Hypoxia activates the capacity of tumor-associated carbonic anhydrase IX to acidify extracellular pH," FEBS Letters, vol. 577, no. 3, pp. 439445, 2004.

[135] J. Chiche, K. Ilc, J. Laferrière et al., "Hypoxia-inducible carbonic anhydrase IX and XII promote tumor cell growth by counteracting acidosis through the regulation of the intracellular $\mathrm{pH}$," Cancer Research, vol. 69, no. 1, pp. 358-368, 2009.

[136] M. E. Lindholm, H. Fischer, L. Poellinger et al., "Negative regulation of HIF in skeletal muscle of elite endurance athletes: a tentative mechanism promoting oxidative metabolism," The American Journal of Physiology-Regulatory, Integrative and Comparative Physiology, vol. 307, no. 3, pp. R248-R255, 2014.

[137] J. O. Holloszy and F. W. Booth, "Biochemical adaptations to endurance exercise in muscle," Annual Review of Physiology, vol. 38, pp. 273-291, 1976.

[138] M. J. N. McDonagh and C. T. M. Davies, "Adaptive response of mammalian skeletal muscle to exercise with high loads," European Journal of Applied Physiology and Occupational Physiology, vol. 52, no. 2, pp. 139-155, 1984.

[139] M. Kon, N. Ohiwa, A. Honda et al., "Effects of systemic hypoxia on human muscular adaptations to resistance exercise training," Physiological Reports, vol. 2, no. 6, Article ID e12033, 2014.

[140] V. I. Bushuev, G. Y. Miasnikova, A. I. Sergueeva et al., "Endothelin-1, vascular endothelial growth factor and systolic 
pulmonary artery pressure in patients with Chuvash polycythemia," Haematologica, vol. 91, no. 6, pp. 744-749, 2006.

[141] S. O. Ang, H. Chen, K. Hirota et al., "Disruption of oxygen homeostasis underlies congenital Chuvash polycythemia," Nature Genetics, vol. 32, no. 4, pp. 614-621, 2002.

[142] F. Formenti, D. Constantin-Teodosiu, Y. Emmanuel et al., "Regulation of human metabolism by hypoxia-inducible factor," Proceedings of the National Academy of Sciences of the United States of America, vol. 107, no. 28, pp. 12722-12727, 2010.

[143] M. A. Creager, J. W. Olin, J. J. F. Belch et al., "Effect of hypoxiainducible factor- $1 \alpha$ gene therapy on walking performance in patients with intermittent claudication," Circulation, vol. 124, no. 16, pp. 1765-1773, 2011.

[144] C. M. R. le Moine, A. J. Morash, and G. B. McClelland, "Changes in HIF- $1 \alpha$ protein, pyruvate dehydrogenase phosphorylation, and activity with exercise in acute and chronic hypoxia," American Journal of Physiology: Regulatory Integrative and Comparative Physiology, vol. 301, no. 4, pp. R1098-R1104, 2011.

[145] R. Mounier, V. Pialoux, B. Roels et al., "Effect of intermittent hypoxic training on HIF gene expression in human skeletal muscle and leukocytes," European Journal of Applied Physiology, vol. 105, no. 4, pp. 515-524, 2009.

[146] H. Niemi, K. Honkonen, P. Korpisalo et al., "HIF-1alpha and HIF-2alpha induce angiogenesis and improve muscle energy recovery," European Journal of Clinical Investigation, vol. 44, no. 10, pp. 989-999, 2014.

[147] T. Drevytska, B. Gavenauskas, S. Drozdovska, V. Nosar, V. Dosenko, and I. Mankovska, "HIF-3 $\alpha$ mRNA expression changes in different tissues and their role in adaptation to intermittent hypoxia and physical exercise," Pathophysiology, vol. 19, no. 3, pp. 205-214, 2012. 


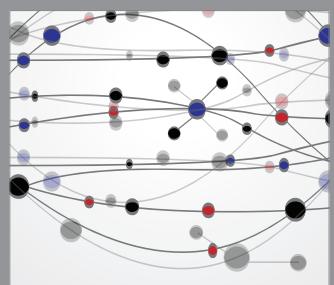

The Scientific World Journal
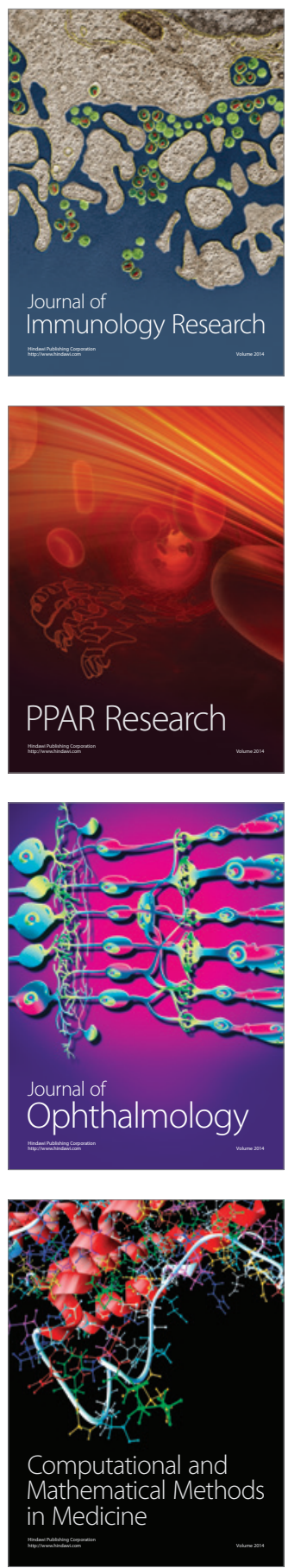

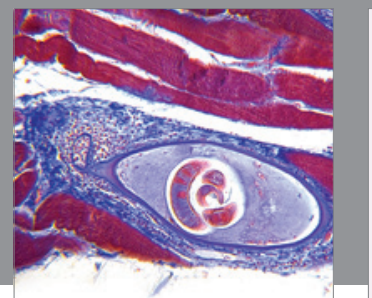

Gastroenterology

Research and Practice
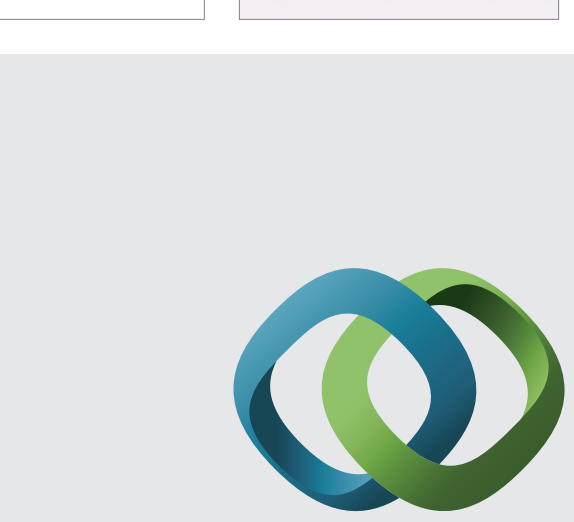

\section{Hindawi}

Submit your manuscripts at

http://www.hindawi.com
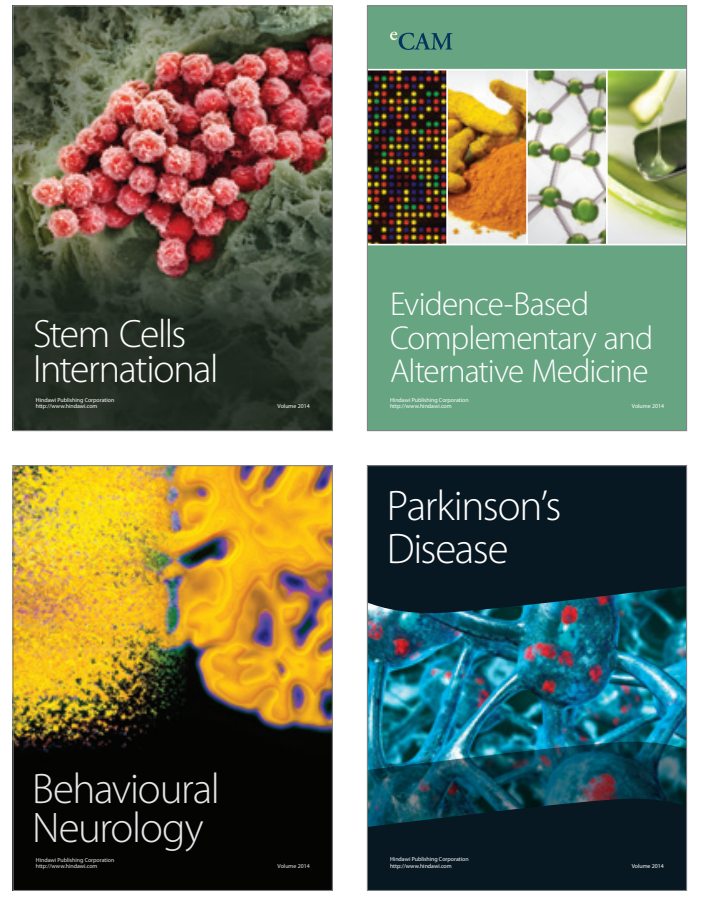
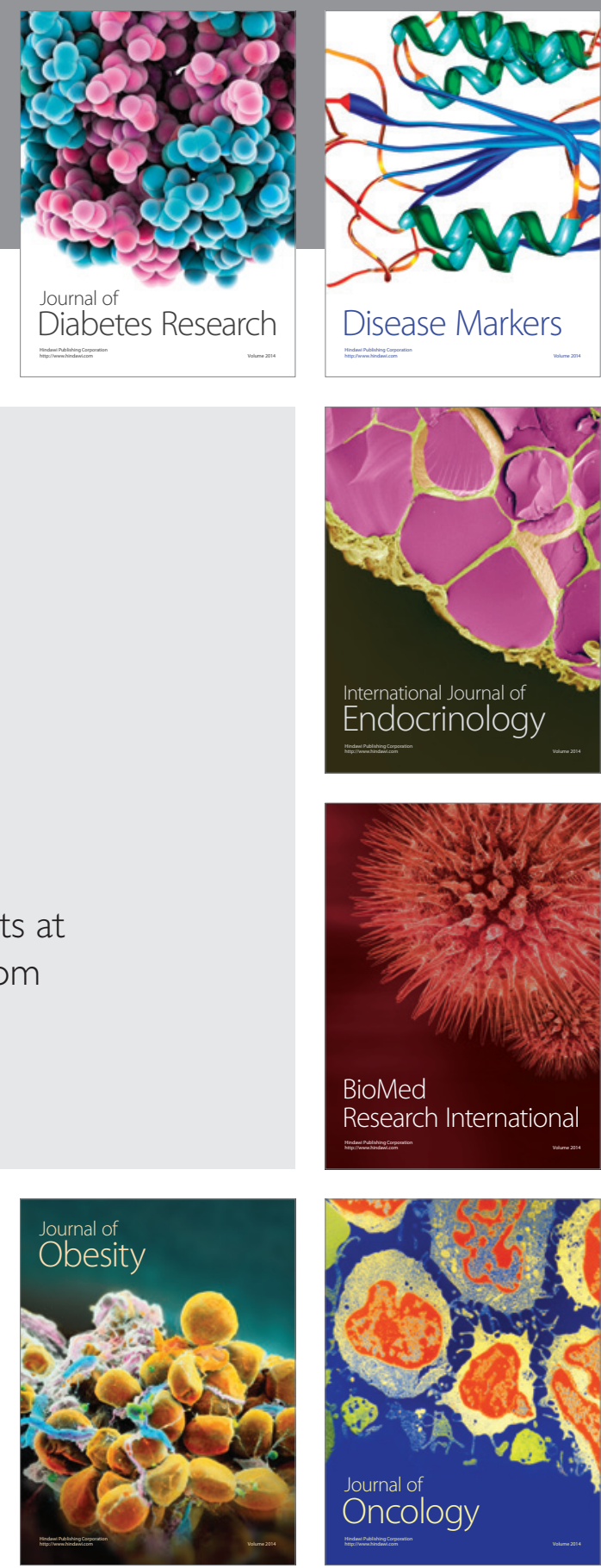

Disease Markers
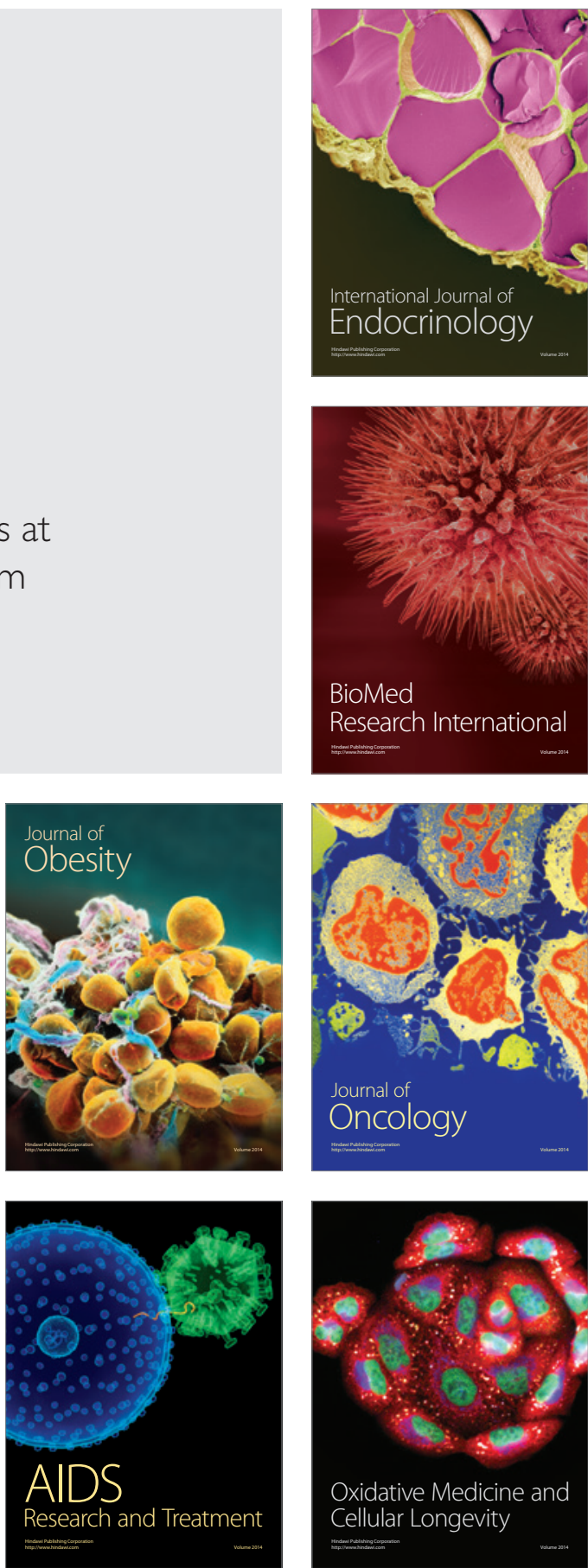